\title{
Teaching and Learning in Interdisciplinary Higher Education: A Systematic Review
}

\author{
Elisabeth J. H. Spelt • Harm J. A. Biemans • Hilde Tobi • \\ Pieternel A. Luning • Martin Mulder
}

Published online: 10 November 2009

(C) The Author(s) 2009. This article is published with open access at Springerlink.com

\begin{abstract}
Interdisciplinary higher education aims to develop boundary-crossing skills, such as interdisciplinary thinking. In the present review study, interdisciplinary thinking was defined as the capacity to integrate knowledge of two or more disciplines to produce a cognitive advancement in ways that would have been impossible or unlikely through single disciplinary means. It was considered as a complex cognitive skill that constituted of a number of subskills. The review was accomplished by means of a systematic search within four scientific literature databases followed by a critical analysis. The review showed that, to date, scientific research into teaching and learning in interdisciplinary higher education has remained limited and explorative. The research advanced the understanding of the necessary subskills of interdisciplinary thinking and typical conditions for enabling the development of interdisciplinary thinking. This understanding provides a platform from which the theory and practice of interdisciplinary higher education can move forward.
\end{abstract}

Keywords Interdisciplinary thinking - Interdisciplinary higher education · Systematic review

Various groups of professionals are increasingly confronted with complex issues like food quality (Luning and Marcelis 2006) or biodiversity conservation (Warren 2006). In order to deal with these issues, professionals need to be able to critically analyze, conceptualize, and synthesize knowledge and to reach conclusions on the basis of ambiguous information (Tynjälä et al. 2006). In response, higher education is increasingly called on to train

E. J. H. Spelt $(\bowtie) \cdot$ H. J. A. Biemans $\cdot$ M. Mulder

Education and Competence Studies Group, Department of Social Sciences, Wageningen University, P.O. Box 8130, 6700 EW Wageningen, The Netherlands

e-mail: Elsbeth.Spelt@wur.nl

H. Tobi

Research Methodology Group, Department of Social Sciences,

Wageningen University, Wageningen, The Netherlands

P. A. Luning

Product Design and Quality Management Group, Department of Agrotechnology and Food Sciences, Wageningen University, Wageningen, The Netherlands 
students to become capable of dealing with such complex issues in both scientific and professional environments (Jacobson and Wilensky 2006; Roehler et al. 1998).

Interdisciplinarity can help to address today's complex issues since it is believed that a crossdisciplinary approach facilitates a comprehensive understanding (Newell 2007). This belief has led to an increased interest in interdisciplinary higher education over the years (Newell 2009). In comparison with traditional higher education, which focuses on domain-specific knowledge and general skills development, this kind of higher education also aims to develop boundarycrossing skills. Boundary-crossing skills are, for instance, the ability to change perspectives, to synthesize knowledge of different disciplines, and to cope with complexity.

Unlike multidisciplinarity, which is additive, interdisciplinarity is integrative: Knowledge of different disciplines is contrasted and changed by integration (Klein 1990). This integration or synthesis of knowledge is seen as the defining characteristic of interdisciplinarity. As a consequence, the ability to synthesize or integrate is considered as a beneficial learning outcome of interdisciplinary higher education. In that case, the learning outcome is called interdisciplinary understanding or interdisciplinary thinking. Boix Mansilla et al. (2000, p. 219) proposed the following definition of interdisciplinary understanding, "The capacity to integrate knowledge and modes of thinking in two or more disciplines or established areas of expertise to produce a cognitive advancement — such as explaining a phenomenon, solving a problem, or creating a product - in ways that would have been impossible or unlikely through single disciplinary means." This definition builds on a performance view of understanding, meaning that individuals understand a concept when they are able to apply it — or think with it - accurately and flexibly in novel situations (Boix Mansilla et al. 2000).

According to this definition, interdisciplinary thinking can be considered as a complex cognitive skill that consists of a number of subskills (Van Merriënboer 1997), such as the ability to change disciplinary perspectives and create meaningful connections across disciplines. Interdisciplinary thinking does not occur spontaneously, it can take a considerable amount of time for students to achieve an adequate level of expertise in its practice. In addition, students need help in order to be able to synthesize two or more disciplines. All too often a curriculum is called interdisciplinary when it is actually multidisciplinary: Multiple perspectives are presented without any support for the integration of disciplinary knowledge throughout the curriculum. As a consequence, in curricula on food studies, for instance, students lack the ability to integrate the required disciplinary knowledge of food processing and food microbiology to keep bacterial growth within food safety criteria. Specific support and learning tasks intended to develop interdisciplinary thinking appear to be important.

Students have problems of working across disciplines, working in different disciplines, and synthesizing different disciplines. This poses difficulties for the development of interdisciplinary thinking in interdisciplinary higher education. These student problems may be caused by disciplinary differences in epistemologies, discourses, and ways of teaching (Bradbeer 1999). In addition, curricula that aim to develop interdisciplinary thinking on a broad scale are likely to experience more difficulties than curricula that aim to develop interdisciplinary thinking on a narrow scale. This is by virtue of the fact that, in contrast to narrow interdisciplinary thinking, broad interdisciplinary thinking requires the integration of disciplines across sciences (Newell 2007). To illustrate, the aforementioned example of integration in food safety concerns interdisciplinary thinking on a narrow scale. In the case of broad interdisciplinary thinking, students are taught to integrate knowledge of sciences like food processing and microbiology as well as social sciences, such as management and psychology, to realize safe food production without contamination by employees (Luning and Marcelis 2009). This means that students also need to overcome differences between 
sciences. Explicit attention to these disciplinary and scientific differences appears to be a typical condition for enabling the development of interdisciplinary thinking.

Considering the complexity of teaching and learning interdisciplinary thinking, interdisciplinary higher education faces challenges in accomplishing both broad and narrow interdisciplinary thinking among its students. Realizing desired learning outcomes demands consistent and well-designed learning environments within a coherent and learner-centered curriculum (Ten Dam et al. 2004). For this reason, curriculum and course developers need a comprehensive understanding of the typical conditions that underpin the development of interdisciplinary thinking (Stefani 2009). This necessitates, for example, gaining insight into the extent to which students need to be equipped with knowledge of different disciplines as well as didactic ways of enabling integration (Chen et al. 2009). However, in view of the lack of an applicable teaching and learning model, it is necessary to examine the literature to seek a basis for this kind of higher education. This line of reasoning motivated the present review of the scientific research on teaching and learning interdisciplinary thinking in interdisciplinary higher education.

\section{Review Framework}

The objectives of the review were to systematically identify, critically analyze, and discuss scientific research on teaching and learning interdisciplinary thinking in interdisciplinary higher education. For this purpose, the theory of Biggs (2003) was used as a frame of reference; it provided an organized way of reviewing the literature that corresponded well with our line of reasoning. This theory describes a comprehensive model for teaching and learning in higher education. In particular, teaching and learning are conceived as an interacting system of four components: student, learning environment, learning process, and learning outcomes (Biggs 1993). Such a model might enable curriculum and course developers in interdisciplinary higher education to gain a comprehensive understanding of teaching and learning interdisciplinary thinking. In addition, the model follows the alignment principle, which means that teaching and learning activities are aligned with desired learning outcomes. This principle leads to an outcome-based approach to teaching and learning that facilitates coherent and pedagogically underpinned curriculum design.

According to Biggs (2003), the components student, learning environment, and learning process represent several characteristics influencing the learning outcomes. In the present study, the student and learning environment components were similar to Biggs (2003). Student characteristics are brought into the learning environment by the student, for instance, prior knowledge and skills. In addition, learning environment addressed situational characteristics like teaching and assessment methods, which are decided by the institution, curriculum, and course developers. The component learning process in this study addressed learning process characteristics and learning activities, such as the sequencing of specific learning activities. The component learning outcomes of Biggs' theory (2003) were defined as interdisciplinary thinking and represented subskills that constitute the complex cognitive skill interdisciplinary thinking (Van Merriënboer 1997).

Figure 1 shows the four components used in this review study in accordance with the general teaching and learning model of Biggs (2003). As shown by the Conceptual Review Framework (see Fig. 1), the learning outcome interdisciplinary thinking is determined by the other components student, learning environment, and learning process interacting with each other. The general direction of interaction, represented by the bold arrows, follows that of Biggs (2003): The components student and learning environment (presage level) are 
Fig. 1 Conceptual Review Framework, adapted from Biggs (2003)

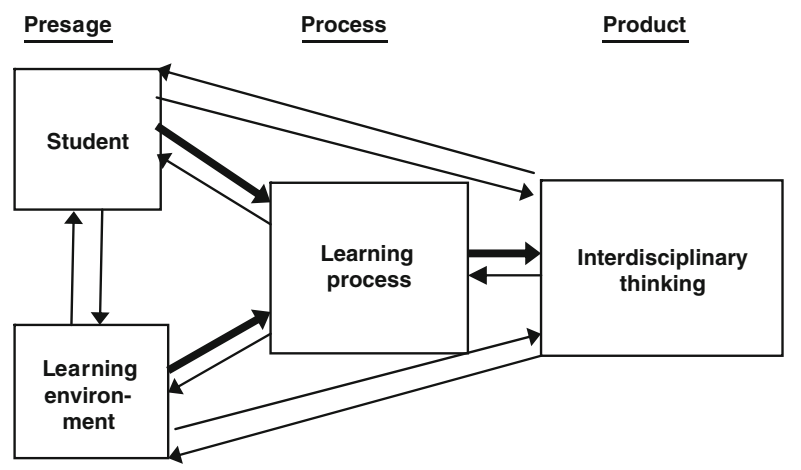

precursors to the learning process and jointly produce the activities students undertake for a given learning task (learning process level), and the learning process in turn produces the learning outcome interdisciplinary thinking (product level). All components are connected by light arrows (see Fig. 1) in order to demonstrate the conceptualization of teaching and learning as an interactive system (Biggs 1993).

The main purpose of this review was to identify the subskills constituting the component interdisciplinary thinking and typical conditions for developing interdisciplinary thinking as present within the components student, learning environment, and learning process. Using the outcome-based perspective of Biggs' theory (2003), five research questions were formulated:

1. Which subskills that constitute interdisciplinary thinking within the context of interdisciplinary higher education are mentioned?

2. Which student conditions that influence interdisciplinary thinking within the context of interdisciplinary higher education are mentioned?

3. Which learning environment conditions that influence interdisciplinary thinking within the context of interdisciplinary higher education are mentioned?

4. Which learning process conditions that influence interdisciplinary thinking within the context of interdisciplinary higher education are mentioned?

5. Which relationships between student, learning environment, and learning process conditions and interdisciplinary thinking within the context of interdisciplinary higher education are mentioned?

The present review study explored these research questions by (a) describing and (b) evaluating scientific research into teaching and learning in interdisciplinary higher education.

\section{Method}

The review process consisted of the four stages described below.

Formulation of inclusion and exclusion criteria

Before searching the literature, the following inclusion criteria were formulated. First, each publication should be relevant, meaning that the publication should examine teaching and learning in interdisciplinary higher education within the scope of the Conceptual Review Framework (see Fig. 1). Second, each publication should be peer reviewed. Third, publications written in English, German, and Dutch were included, as the authors could 
read and understand these languages. Finally, the time span of the literature search was limited to 1992-2009 to provide an overview of the most recent research in this field. Publications reporting on individual faculty experiences, courses, curricula, or projects without any scientific examination of teaching and learning were excluded. Publications on institutional or organizational topics such as the implementation of interdisciplinary higher education fell outside the scope of this review.

Development of a search strategy

In order to develop a search strategy appropriate to the main purpose of this review, various search terms were listed, such as multidisciplinary learning and integrated approach. After careful consideration of the consequences of removing potential search terms, the following search terms were identified as being the most informative: interdisciplinary thinking, interdisciplinary understanding, interdisciplinary teaching, interdisciplinary course, interdisciplinary courses, interdisciplinary curriculum, interdisciplinary curriculums, interdisciplinary curricula, interdisciplinary program, interdisciplinary programs, interdisciplinary programmes, interdisciplinary education, and interdisciplinary learning, each in combination with undergraduate, graduate, higher education, and university. Quotation marks were used to search for phrases. The chosen search strategy focused on title, abstract, and keywords in order to obtain publications with a clear focus on teaching and learning within the context of interdisciplinary higher education. The chosen search terms followed the four components of the Conceptual Review Framework (see Fig. 1). For the component student, no search terms were identified since the term interdisciplinary student was not used and student only resulted in too many irrelevant publications. In view of this, it was hoped that the search terms identified for the components interdisciplinary thinking, learning environment, and learning process would reveal publications concerning the component student.

Identification of relevant publications

Four databases were searched: the Educational Resources Information Centre (ERIC) catalog, the Science Citation Index Expanded (SCI-EXPANDED), the Social Sciences Citation Index (SSCI), and the Arts \& Humanities Citation Index (A\&HCI); the latter three provided by the Web of Science ${ }^{\circledR}$. The abstracts of the publications resulting from the aforementioned search strategy were screened for relevancy. If the abstract did not provide sufficient information, then the full text was scanned to determine whether or not the publication met the inclusion criteria. The identification process was carried out twice by the first author for two reasons: (a) to be sure that all relevant publications were included and (b) to categorize the nonrelevant publications. Where the identified relevant publications reported on the results of the same study, the publication with the most extensive coverage of the reported study was included in the analysis.

\section{Critical analysis and exploration}

Following careful reading, the critical analysis was carried out using a self-devised literature review form based on the review framework adopted in this study. This provided the scope for the description and evaluation of the found publications. The literature review form also served to standardize the critical analysis. The form consisted of two parts: (a) questions intended to afford insight into the research design characteristics of the publications, thereby enabling the description of scientific research 
into teaching and learning in interdisciplinary higher education and (b) questions formulated to embody the principles of Biggs' theory, thereby enabling the evaluation of the scientific research into teaching and learning in interdisciplinary higher education. The formulated questions were applicable to the analysis of theoretical publications as well as empirical research. The form contained descriptive questions with, in most cases, a shortanswer possibility. A detailed answer should always be provided to clarify the given short answers. In order to explore our research questions, only typical conditions for enabling the development of interdisciplinary thinking were included. Conversely, general conditions such as student motivation or congruence between learning goals and assessment were not included. Once all the publications had been reviewed and the review forms had been completed, the identified research design characteristics and the identified presence of Biggs' principles were examined. In addition, a content analysis of the extracted subskills and conditions was conducted. This analysis included two steps: (a) all extracted subskills and conditions were categorized according to the four components of the Conceptual Review Framework (see Fig. 1) and (b) similar subskills or conditions were grouped and labeled.

\section{Results and Discussion}

Description of scientific research into teaching and learning in interdisciplinary higher education

The search resulted in 309 unique publications. Of these, 14 publications met the aforementioned criteria for inclusion. While two relevant publications reported on the same empirical study results, only the publication with the most extensive coverage was included. Of those 13 relevant publications, ten were empirical and three were theoretical studies. The publications that were removed included 172 describing individual faculty experiences, courses, curricula, or projects and 73 publications that fell outside the scope of this review. Also excluded were 50 publications on a different topic.

The majority of the reviewed publications (11 out of 13) were published in the twentyfirst century and in the domain of education (nine out of 13). All relevant publications were written in English. Three publications - Boix Mansilla and Duraising (2007) and Nikitina $(2005,2006)$ - concerned one particular research project on interdisciplinarity at Harvard University.

A broad range of topics on teaching and learning was researched. This resulted in: potential frameworks (seven out of 13), best practices (four out of 13), and essential conditions (two out of 13). To start with the proposed frameworks, these publications considered the following teaching and learning topics: an adaptation of Biggs and Collis' Structure of Observed Learning Outcome (SOLO) taxonomy to illustrate interdisciplinary learning (Ivanitskaya et al. 2002), a proposed research agenda based on teaching and learning theories to encourage research in the field of interdisciplinary higher education (Lattuca et al. 2004), a framework illustrating three major cognitive movements in interdisciplinary thought (Nikitina 2005), three strategies for interdisciplinary teaching (Nikitina 2006), four dimensions of a potential interdisciplinary pedagogy (Manathunga et al. 2006), an empirically grounded framework for assessing students' interdisciplinary work (Boix Mansilla and Duraising 2007), and a framework for conceptualizing interdisciplinary classroom communication (Woods 2007). Second, best practices dealt with the relationship between disciplinary background and interdisciplinary education (Newell 1992), with the 
lack of adequate and appropriate methods for assessing interdisciplinary higher education programs (Field and Lee 1992), with the experiences of graduate students who pursued interdisciplinary studies (Graybill et al. 2006), and a successful course approach (Eisen et al. 2009). Third, the following essential conditions were identified through the evaluation of two interdisciplinary training programs: participation, training in group skills, information sharing, networking, critical reflection (Gilkey and Earp 2006), participation in a collaborative interdisciplinary team project, and faculty mentors (Misra et al. 2009).

As a rule, the empirical studies (ten out of 13) used surveys, interviews, observations, product appraisal, and reflection on experiences as their research methods. The theoretical studies (three out 13) put forward several theories such as Perry and Vygotsky (e.g., Lattuca et al. 2004) to describe the phenomenon under examination, but lacked empirical evidence. The educational context of the reported studies varied: undergraduate and graduate curricula in sciences, social sciences, and humanities and the studies were mainly conducted in the United States (12 out of 13).

Evaluation of scientific research into teaching and learning in interdisciplinary higher education

The evaluation based on the principles of Biggs' theory (2003) showed that all publications reviewed were explorative. The research field is still in the phase of attempting to deepen the understanding of the nature of interdisciplinary higher education. This formative stage of development can be attributed to the perceived lack of specific educational models and empirical research in this field (e.g., Woods 2007). Accordingly, strong empirical studies addressing the research questions of this review study were lacking.

The evaluation also revealed the absence of a comprehensive view of teaching and learning; the reviewed publications adopted a narrower focus. Using the Conceptual Review Framework (see Fig. 1) to categorize the aforementioned researched teaching and learning topics resulted in nine publications that addressed mainly learning environment, two publications that addressed mainly interdisciplinary thinking, two publications that addressed mainly learning process, and zero publications that addressed mainly student. In addition, there was slight evidence of the outcome-based approach as adopted in this review study. Three of the reviewed publications (Boix Mansilla and Duraising 2007; Nikitina 2005; Woods 2007) tend towards the outcome-based approach. Concerning the conceptualization of interdisciplinary thinking, Boix Mansilla and Duraising defined interdisciplinary thinking in a manner similar to that used in this review study. The other publications referred to the synthesis or integration characteristic of interdisciplinarity.

The content analysis resulted in an understanding of potential subskills that constitute interdisciplinary thinking and potential conditions for enabling the development of interdisciplinary thinking (see Table 1). Despite the differing focus of the reviewed publications, similarities in subskills and conditions were noticed. To illustrate, phased with gradual advancement (see Table 1) was suggested by three publications (Ivanitskaya et al. 2002; Manathunga et al. 2006; Woods 2007). Similar subskills and conditions were subsequently grouped and labeled. While conditions and subskills were mentioned in several of the reviewed publications within the context of a narrower focus as referred to above, it was necessary to synthesize the insights found to construct a full picture of teaching and learning in interdisciplinary higher education according to Biggs' theory. In view of the nature of the present research, the need for empirical evidence is recognized. 
Table 1 Overview of Potential Subskills and Conditions

Potential subskills and conditions for interdisciplinary higher education

\begin{tabular}{|c|c|c|}
\hline \multirow[t]{5}{*}{ Interdisciplinary thinking } & Having knowledge & Knowledge of disciplines \\
\hline & & Knowledge of disciplinary paradigms \\
\hline & & Knowledge of interdisciplinarity \\
\hline & Having skills & Higher-order cognitive skills \\
\hline & & Communication skills \\
\hline \multirow[t]{8}{*}{ Student } & Personal characteristics & Curiosity \\
\hline & & Respect \\
\hline & & Openness \\
\hline & & Patience \\
\hline & & Diligence \\
\hline & & Self-regulation \\
\hline & Prior experiences & Social \\
\hline & & Educational \\
\hline \multirow[t]{12}{*}{ Learning environment } & Curriculum & Balance between disciplinarity and interdisciplinarity \\
\hline & & $\begin{array}{l}\text { Disciplinary knowledge inside or outside courses } \\
\text { on interdisciplinarity }\end{array}$ \\
\hline & Teacher & Intellectual community focused on interdisciplinarity \\
\hline & & Expertise of teachers on interdisciplinarity \\
\hline & & Consensus on interdisciplinarity \\
\hline & & Team development \\
\hline & & Team teaching \\
\hline & Pedagogy & Aimed at achieving interdisciplinarity \\
\hline & & Aimed at achieving active learning \\
\hline & & Aimed at achieving collaboration \\
\hline & Assessment & Of students' intellectual maturation \\
\hline & & Of interdisciplinarity \\
\hline \multirow[t]{6}{*}{ Learning process } & Pattern & Phased with gradual advancement \\
\hline & & Linear \\
\hline & & Iterative \\
\hline & & Milestones with encountering questions \\
\hline & Learning activities & Aimed at achieving interdisciplinarity \\
\hline & & Aimed at achieving reflection \\
\hline
\end{tabular}

Table 1 shows that, in becoming capable of interdisciplinary thinking, the reviewed publications suggested the importance of two categories having knowledge as well as having skills. Each category consists of a number of subskills such as knowledge of disciplinary paradigms and communication skills. In addition, in enabling interdisciplinary thinking, the publications suggested the importance of eight categories (see Table 1): personal characteristics, prior experiences (student component), curriculum, teacher, pedagogy, assessment (learning environment component), pattern, and learning activities (learning process component). Each category consists of a number of typical conditions, ranging from two to six, such as openness, intellectual community focused on interdisciplinarity, pedagogy aimed at achieving collaboration, and learning activities aimed at achieving reflection. 
Exploration of research questions

\section{Which subskills that constitute interdisciplinary thinking within the context of interdisciplinary higher education are mentioned?}

Five subskills, divided into two categories, seemed to be important to become capable of interdisciplinary thinking (see Table 1). The first category, having knowledge, consists of three subskills: knowledge of disciplines, knowledge of disciplinary paradigms, and knowledge of interdisciplinarity. These subskills suggest the importance of disciplinary declarative, procedural, and paradigm knowledge, such as the characteristics of natural and social scientific theories as, for instance, classified by Szostak (2003), supplemented with knowledge of interdisciplinarity, such as knowing the differences between disciplinarity, multidisciplinarity, and interdisciplinarity. Acquisition of these types of knowledge appears to be required for enabling students to step beyond the disciplinary theories and methods in order to make connections between disciplines, to identify disciplinary contradictions, and to consider opportunities for integration at a meta-level (Boix Mansilla and Duraising 2007). In particular, explicit attention to the students' exposure to disciplines and metacoordination seems to be important to avoid their feeling overwhelmed and losing the curricular thread (Eisen et al. 2009; Manathunga et al. 2006).

The other category, having skills, consists of higher-order skills and communication skills. Higher-order skills indicate the necessary ability to search, identify, understand, critically appraise, connect, and integrate theories and methods of different disciplines and to apply the resulting cognitive advancement together with continuous evaluation (Boix Mansilla and Duraising 2007; Ivanitskaya et al. 2002; Woods 2007). Inherently, this also requires the ability to change disciplinary perspectives, to switch between depth and breadth, and to transfer new knowledge structures to other appropriate contexts. Communication skills indicate the necessity of learning the language of discourse of different disciplines in order to be able to negotiate meaning, resolve epistemological differences, develop shared understanding, and communicate cognitive advancements to a broad audience (Manathunga et al. 2006; Woods 2007).

\section{Which student conditions that influence interdisciplinary thinking within the context of interdisciplinary higher education are mentioned?}

Eight student conditions, divided into two categories, seemed to be important to enabling interdisciplinary thinking (see Table 1).The first category, personal characteristics, includes six conditions. The three conditions curiosity, respect, and openness point at the necessary appreciative attitude towards other disciplines (Bruce et al. 2004). Importantly, students appeared to have a wide variation in attitude towards other disciplines (Woods 2007). The other three conditions patience, diligence, and self-regulation likely refer to characteristics essential to enabling the production of a cognitive advancement. The second category, prior experiences, includes the two conditions social experiences and educational experiences. These conditions point at, for instance, students' experienced way(s) of thinking, styles of teaching, and beliefs about the nature of knowledge and learning (Lattuca et al. 2004).

Which learning environment conditions that influence interdisciplinary thinking within the context of interdisciplinary higher education are mentioned?

Twelve learning environment conditions, divided into four categories, seemed to be important to enabling interdisciplinary thinking (see Table 1). The first category, 
curriculum, consists of two conditions: balance between disciplinarity and interdisciplinarity and disciplinary knowledge inside or outside courses on interdisciplinarity. In particular, an overarching framework that links and sequences curricular content seems to be essential to provide both context and a roadmap for learning (Newell 1992). The second category, teacher, contains five conditions: intellectual community focused on interdisciplinarity, expertise of teachers on interdisciplinarity, consensus on interdisciplinarity, team development, and team teaching. These conditions refer to the importance of teacher teams and their professional development in interdisciplinarity as a means of facilitating the necessary understanding and integration of each others' disciplines and of realizing a safe environment in which to mentor students on their journey towards interdisciplinarity (Gilkey and Earp 2006; Graybill et al. 2006; Newell 1992). The third category, pedagogy, includes three conditions: pedagogy aimed at achieving interdisciplinarity, pedagogy aimed at achieving active learning, and pedagogy aimed at achieving collaboration. These conditions seem to point to the necessity of learning tasks that actively engage students in applying knowledge rather than memorizing facts, in collaboration with peers in other disciplines to encourage an appreciation of ambiguity (Manathunga et al. 2006). In addition, such learning tasks need to provide students with the opportunity to gain experience of inquiry activities typical of interdisciplinarity, for instance, the negotiation of common ground (Woods 2007). The fourth category, assessment, includes the condition assessment of students' intellectual maturation, which seems to point to the importance of a formative assessment of interdisciplinary thinking subskills. This category also includes the condition assessment of interdisciplinarity that suggests a summative assessment of the learning outcome interdisciplinary thinking. Both conditions suggest assessment instruments that include a combined development and performance perspective to help teachers as well as students to analyze the progression of interdisciplinary thinking (Field and Lee 1992; Ivanitskaya et al. 2002; Woods 2007).

Which learning process conditions that influence interdisciplinary thinking within the context of interdisciplinary higher education are mentioned?

Six learning process conditions, divided into two categories, seemed to be important to enabling interdisciplinary thinking (see Table 1). The first category, pattern, contains four conditions: phased with gradual advancement, linear, iterative, and milestones with encountering questions. These four conditions seem to point to the need for a gradual, linear, phased pattern combined with predetermined learning outcomes that serve as milestones for each phase in which students are repeatedly exposed to interdisciplinary thinking (Graybill et al. 2006; Ivanitskaya et al. 2002; Manathunga et al. 2006; Woods 2007). It has been suggested that this development process may follow that of Biggs' SOLO taxonomy (Ivanitskaya et al. 2002) or intellectual maturation theories such as that of Perry (Field and Lee 1992). The second category, learning activities, includes the conditions learning activities aimed at achieving interdisciplinarity and learning activities aimed at achieving reflection. Both conditions likely refer to the need for learning activities aiming at the acquisition of subskills of interdisciplinary thinking. In particular, provoking students in contrasting and conflicting disciplinary perspectives combined with developing a critical stance seems to be essential to stimulate students to depart from their notion of absolute knowledge (Ivanitskaya et al. 2002; Lattuca et al. 2004). 
Which relationships between student, learning environment, and learning process conditions and interdisciplinary thinking within the context of interdisciplinary higher education are mentioned?

No empirical evidence was provided by the publications reviewed regarding the relationships between student, learning environment, and learning process conditions and interdisciplinary thinking. However, the review results, as presented in Table 1, do provide the basis for several hypothetical relationships between the identified conditions and the learning outcome interdisciplinary thinking. It can be hypothesized, for instance, that the student condition curiosity and the learning environment condition team teaching have a positive relationship with the development of interdisciplinary thinking. In addition, phased with gradual advancement appears to be a desirable condition of the learning process that is positively related with the learning outcome interdisciplinary thinking and so on. Importantly, a proper balance between knowledge and skills development, repeated exposure, and scaffolding appears to be required to enable interdisciplinary thinking (Ivanitskaya et al. 2002; Manathunga et al. 2006; Woods 2007).

\section{Conclusions and Considerations}

This literature review set out to disclose the subskills that constitute interdisciplinary thinking and to unravel the typical student, learning environment, and learning process conditions that enable interdisciplinary thinking development in interdisciplinary higher education. The first finding is that despite repeated acknowledgement of the lack of scientific research in the field of teaching and learning in interdisciplinary higher education (e.g., Lattuca et al. 2004), to date, such research has been limited and explorative. Second, the present review should be regarded as one of the first scientific studies to offer a clear and comprehensive view of the teaching and learning interdisciplinary thinking in interdisciplinary higher education. Third, the adopted outcome-based approach, consistent with the theory of Biggs (2003), also appears to be innovative in interdisciplinary higher education presumably because interdisciplinary higher education is still being defined not in terms of what students gain in ability but in terms of its own pedagogical characteristics. It is desirable that the proposed performance view of interdisciplinary higher education be adopted since: (a) recent research (e.g., Misra et al. 2009) has exemplified the difficulty in realizing the beneficial synthesis or integration outcome and (b) it will promote the unification of terminology as exemplified in the present review study, the need for which has been identified (e.g., Manathunga et al. 2006). Fourth, the research designs in the reviewed publications inevitably differed in quality. In this review study, the methodological quality of the research designs was not taken into account as such. However, generally speaking, it is clear from the review results that, in order to move scientific research in this field a step forward, strong empirical studies are needed.

The present systematic review study has advanced the understanding of the potential subskills and conditions (see Table 1) that can serve as the basis for strong empirical studies. The subskills of interdisciplinary thinking that were obtained are: knowledge of disciplines, knowledge of disciplinary paradigms, knowledge of interdisciplinarity, higherorder cognitive skills, and communication skills. The student conditions that were obtained are: curiosity, respect, openness, patience, diligence, self-regulation, social experiences, and 
educational experiences. The learning environment conditions that were obtained are: balance between disciplinarity and interdisciplinarity, disciplinary knowledge inside or outside courses on interdisciplinarity, intellectual community focused on interdisciplinarity, expertise of teachers on interdisciplinarity, consensus on interdisciplinarity, team development, team teaching, pedagogy aimed at achieving interdisciplinarity, pedagogy aimed at achieving active learning, pedagogy aimed at achieving collaboration, assessment of students' intellectual maturation, and assessment of interdisciplinarity. The learning process conditions that were obtained are: phased with gradual advancement, linear, iterative, milestones with encountering questions, learning activities aimed at achieving interdisciplinarity, and learning activities aimed at achieving reflection.

Despite the modest number of relevant publications found, this review should be considered as a suitable preparatory study, encouraging others to explore the field of teaching and learning interdisciplinary thinking in more depth. The number of publications was found to be sufficient to explore our research questions. The theory of Biggs (2003) has been helpful in: (a) recognizing similarities in subskills and conditions between the reported studies despite their differing focus and (b) providing an organized way of identifying and categorizing these subskills and conditions. In retrospect, the selected time span of the literature search, languages, scientific literature databases, as well as the search strategy used were adequate for the purposes of this review. Although no specific search terms concerning the component student were included, eight possible conditions could be extracted (see Table 1).

\section{Suggestions for Further Research}

Further research should examine whether empirical evidence can be found for the subskills and conditions obtained in the present study (see Table 1). Strong empirical research is required to test hypothetical relationships between student, learning environment, and learning process conditions and interdisciplinary thinking within the context of interdisciplinary higher education. Such testing would open the way for research into the exact nature of these relationships; for example, the extent of the influence of one factor on another, the stability of such influence, and its mutation over time. Additionally, empirical research should focus on identifying the optimum combination of conditions to enable interdisciplinary thinking. In particular, research into the extent and sequence of knowledge and skills development and the balance between knowledge and skills development is recommended (Ivanitskaya et al. 2002; Manathunga et al. 2006; Woods 2007).

Investigation whether the proposed performance view of curriculum design in interdisciplinary higher education does indeed facilitate the achievement of the learning outcome interdisciplinary thinking is recommended. It would be interesting to investigate if and how the operationalization of the learning outcome interdisciplinary thinking differs along interdisciplinary higher education curricula lines, between curricula with a focus on narrow and broad interdisciplinary thinking, and between educational contexts (Boix Mansilla and Duraising 2007; Nikitina 2005, 2006).

To summarize, while interdisciplinary higher education is commonly practiced nowadays, a surprisingly small body of theory has accumulated. The present systematic review has analyzed some of that theory in order to establish a platform from which the theory of interdisciplinary higher education can be moved forward. It is hoped that this will encourage further empirical research that will lead in time to a framework for interdisciplinary higher education design and will deepen understanding of the nature of teaching and learning interdisciplinary thinking. 
Acknowledgement This research into teaching and learning in interdisciplinary thinking in interdisciplinary higher education was made possible by partial funding received from the lectorate on Food and Health of A.F. Dijkstra of Van Hall Larenstein University of Professional Education, The Netherlands.

Open Access This article is distributed under the terms of the Creative Commons Attribution Noncommercial License which permits any noncommercial use, distribution, and reproduction in any medium, provided the original author(s) and source are credited.

\section{References}

Biggs, J. B. (1993). From theory to practice: A cognitive systems approach. Higher Education Research and Development, 12(1), 73-86.

Biggs, J. B. (2003). Teaching for quality learning at university: What the student does (2nd ed.). Buckingham: Open University Press.

Boix Mansilla, V. \& Duraising, E. D. (2007). Targeted assessment of students' interdisciplinary work: An empirically grounded framework proposed. The Journal of Higher Education, 78(2), 215-237.

Boix Mansilla, V., Miller, W. C., \& Gardner, H. (2000). On disciplinary lenses and interdisciplinary work. In S. Wineburg \& P. Grossman (Eds.), Interdisciplinary curriculum: Challenges of implementation. New York: Teachers College Press.

Bradbeer, J. (1999). Barriers to interdisciplinarity: Disciplinary discourses and student learning. Journal of Geography in Higher Education, 23(3), 381-396.

Bruce, A., Lyall, C., Tait, J., \& Williams, R. (2004). Interdisciplinary integration in Europe: The case of the Fifth Framework programme. Futures, 36(4), 457-470.

Chen, S., Hsu, I. C., \& Wu, C. M. (2009). Evaluation of undergraduate curriculum reform for interdisciplinary learning. Teaching in Higher Education, 14(2), 161-173.

Eisen, A., Hall, A., Soon Lee, T., \& Zupko, J. (2009). Teaching water: Connecting across disciplines and into daily life to address complex societal issues. College Teaching, 57(2), 99-104.

Field, M. \& Lee, R. (1992). Assessment of interdisciplinary programmes. European Journal of Education, 27 (3), 277-283.

Gilkey, M. B. \& Earp, J. A. L. (2006). Effective interdisciplinary training: Lessons from the University of North Carolina's Student Health Action Coalition. Academic Medicine, 81(8), 749-758.

Graybill, J. K., Dooling, S., Shandas, V., Withey, J., Greve, A., \& Simon, G. L. (2006). A rough guide to interdisciplinarity: Graduate student perspectives. Bioscience, 56(9), 757-763.

Ivanitskaya, L., Clark, D., Montgomery, G., \& Primeau, R. (2002). Interdisciplinary learning: Process and outcomes. Innovative Higher Education, 27(2), 95-111.

Jacobson, M. J. \& Wilensky, U. (2006). Complex systems in education: Scientific and educational importance and implications for the learning sciences. The Journal of the Learning Sciences, 15(1), 1134.

Klein, J. T. (1990). Interdisciplinarity: History, theory, and practice. Detroit: Wayne State University Press.

Lattuca, L. R., Voigt, L. J., \& Fath, K. Q. (2004). Does interdisciplinarity promote learning? Theoretical support and researchable questions. The Review of Higher Education, 28(1), 23-48.

Luning, P. A. \& Marcelis, W. J. (2006). A techno-managerial approach in food quality management research. Trends in Food Science \& Technology, 17(7), 378-385.

Luning, P. A. \& Marcelis, W. J. (2009). A food quality management research methodology integrating technological and managerial theories. Trends in Food Science \& Technology, 20(1), 35-44.

Manathunga, C., Lant, P., \& Mellick, G. (2006). Imagining an interdisciplinary doctoral pedagogy. Teaching in Higher Education, 11(3), 365-379.

Misra, S., Harvey, R. H., Stokols, D., Pine, K. H., Fuqua, J., Shokair, S. M., et al. (2009). Evaluating an interdisciplinary undergraduate training program in health promotion research. American Journal of Preventive Medicine, 36(4), 358-365.

Newell, W. H. (1992). Academic disciplines and undergraduate interdisciplinary education: Lessons from the School of Interdisciplinary Studies at Miami University, Ohio. European Journal of Education, 27(3), 211-221.

Newell, W. H. (2007). Decision making in interdisciplinary studies. In G. Morçöl (Ed.), Handbook of decision making. New York: CRC.

Newell, W. H. (2009). Interdisciplinarity in undergraduate general education. In R. Frodeman, J. T. Klein \& C. Mitcham (Eds.), The Oxford handbook on interdisciplinarity. Oxford: Oxford University Press. (In press). 
Nikitina, S. (2005). Pathways of interdisciplinary cognition. Cognition and Instruction, 23(3), 389-425.

Nikitina, S. (2006). Three strategies for interdisciplinary teaching: Contextualizing, conceptualizing, and problem-centring. Journal of Curriculum Studies, 38(3), 251-271.

Roehler, L., Fear, K., \& Herrmann, B. A. (1998). Connecting and creating for learning: Integrating subject matter across the curriculum and the school. Educational Psychology Review, 10(2), 201-225.

Stefani, L. A. J. (2009). Assessment in interdisciplinary and interprofessional programs: Shifting paradigms. In B. Chandramohan \& S. Fallows (Eds.), Interdisciplinary learning and teaching in higher education: Theory and practice. New York: Routledge.

Szostak, R. (2003). Classifying natural and social scientific theories. Current Sociology, 51(1), 27-49.

Ten Dam, G., Van Hout, H., Terlouw, C., \& Willems, J. (2004). Onderwijskunde hoger onderwijs. Assen: Koninklijke Van Gorcum.

Tynjälä, P., Slotte, V., Nieminen, J., Lonka, K., \& Olkinuora, E. (2006). From university to working life: Graduates' workplace skills in practice. In P. Tynjälä, J. Välimaa \& G. Boulton-Lewis (Eds.), Higher education and working life: Collaborations, confrontations and challenges. Amsterdam: Elsevier.

Van Merriënboer, J. J. G. (1997). Training complex cognitive skills: A four-component instructional design model for technical training. Englewood Cliffs: Educational Technology.

Warren, K. (2006). Postgraduate veterinary training in conservation medicine: An interdisciplinary program at Murdoch University, Australia. EcoHealth, 3(1), 57-65.

Woods, C. (2007). Researching and developing interdisciplinary teaching: Towards a conceptual framework for classroom communication. Higher Education, 54(6), 853-866. 